\title{
COSMIC-2 radio occultation temperature, specific humidity, and precipitable water in Hurricane Dorian (2019)
}

\author{
Richard Anthes *, Jeremiah Sjoberg, Therese Rieckh, Tae-Kwon Wee, and Zhen Zeng \\ COSMIC Program, University Corporation for Atmospheric Research, Boulder, Colorado, United States
}

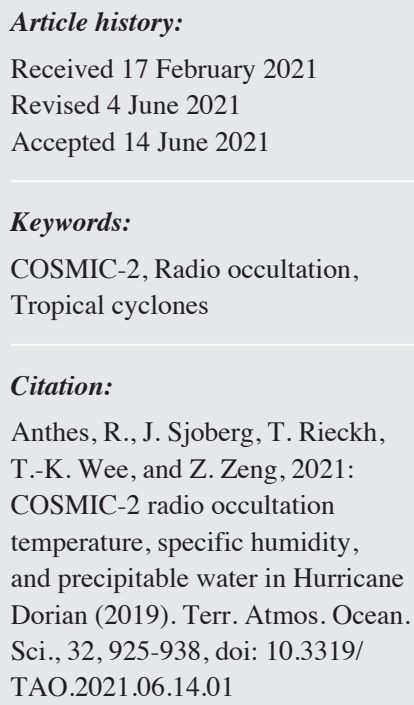

Citation:

Anthes, R., J. Sjoberg, T. Rieckh, T.-K. Wee, and Z. Zeng, 2021: COSMIC-2 radio occultation temperature, specific humidity, and precipitable water in Hurricane Dorian (2019). Terr. Atmos. Ocean. Sci., 32, 925-938, doi: $10.3319 /$ TAO.2021.06.14.01

\begin{abstract}
We consider the accuracy and precision of COSMIC-2 (C2) radio occultation retrievals of temperature, specific humidity, and precipitable water (PW) in Hurricane Dorian (2019) and the larger-scale tropical and subtropical environment by comparing them with ERA5, MERRA-2, and JRA-55 reanalyses. Because of its high signal-to-noise ratio, at least $70 \%$ of the $\mathrm{C} 2$ soundings penetrate to within $1 \mathrm{~km}$ of the surface over the oceans, even in the extremely moist hurricane atmosphere. We compute biases and standard deviations of differences of $\mathrm{C} 2$ temperature and specific humidity with respect to ERA5 and estimate the standard deviation of random errors of $\mathrm{C} 2$ using the three-cornered hat $(3 \mathrm{CH})$ method. The $\mathrm{C} 2$ profiles of mean temperature and specific humidity agree closely with ERA 5 above $2 \mathrm{~km}$, with a temperature bias of less than $0.3 \mathrm{~K}$ and a specific humidity bias of less than $0.3 \mathrm{~g} \mathrm{~kg}^{-1}(15 \%)$. Below $2 \mathrm{~km}, \mathrm{C} 2$ shows a dry bias of up to $2 \mathrm{~g} \mathrm{~kg}^{-1}$ relative to ERA5, which is likely related to factors other than super-refraction. This dry bias below $2 \mathrm{~km}$, which is present in more than $90 \%$ of the profiles, causes a small $(1-2 \%)$ dry bias in PW. The $3 \mathrm{CH}$ estimates of $\mathrm{C} 2$ temperature error standard deviations are less than $0.5 \mathrm{~K}$ throughout most of the troposphere. The $3 \mathrm{CH}$ error estimates of $\mathrm{C} 2$ specific humidity are less than $1.0 \mathrm{~g} \mathrm{~kg}^{-1}(25 \%)$. These estimates are similar to those of ERA5 and smaller than those of MERRA-2 and JRA-55. The 3CH estimates of C2 PW random errors are the smallest of all the data sets. Overall, we conclude that $\mathrm{C} 2$ provides accurate and precise vertical profiles of temperature, water vapor, and precipitable water in the hurricane and its environment.
\end{abstract}

\section{INTRODUCTION}

The atmospheric structure of tropical cyclones (TCs) and their environment presents observational challenges. Satellites, aircraft, radars, radiosondes, and dropsondes provide valuable observations of TCs for research and operational forecasts, but all have their limitations. There are few radiosonde observations over the oceans, infrared and microwave satellite observations are limited by clouds and precipitation, and aircraft and dropsonde observations are expensive and difficult to obtain when TCs are far from land. Radio occultation (RO) observations, which have high vertical resolution and are nearly unaffected by clouds and precipitation, provide important information on temperature and water vapor in TCs. Numerous studies have shown

\footnotetext{
* Corresponding author

E-mail:anthes@ucar.edu
}

the positive impact of RO observations on TC track forecasts and intensity (Huang et al. 2005, 2010; Chen et al. 2009, 2015, 2020; Kueh et al. 2009; Liu et al. 2012). RO observations in the outer environment of TCs have a significant impact on their track forecasts by altering the modeled steering flow, while RO observations within $500 \mathrm{~km}$ of the TC center improve the intensity and cyclogenesis forecasts by enhancing the low- and mid-tropospheric water vapor analysis. Anthes et al. (2003) compared a single CHAMP (Challenging Minisatellite Payload) RO sounding to two nearby radiosondes in Typhoon Toraji (2001) and found close agreement. Chou et al. (2009) found large differences between three dropsondes and COSMIC (Constellation Observing System for Meteorology, Ionosphere, and Climate) RO specific humidity profiles in the vicinity of Typhoon Cimaron (2006), which they attributed to disparities in horizontal scale of the RO and dropsonde observations 
(representativeness differences) in a highly variable specific humidity environment. Vergados et al. (2013) composited $\mathrm{RO}$ data within $3 \mathrm{~h}$ and $600 \mathrm{~km}$ of $42 \mathrm{TC}$ centers to compare azimuthally averaged vertical cross sections of refractivity and relative humidity from RO and ECMWF analyses through TCs. Biondi et al. $(2011,2013,2015)$ used the highvertical-resolution property of RO data to study the cloudtop heights and thermal structure of the upper troposphere/ lower stratosphere of TC.

COSMIC-2 (C2), launched 25 June 2019 (Anthes and Schreiner 2019; Ho et al. 2020b; Schreiner et al. 2020), provides 4000 - $5000 \mathrm{RO}$ soundings on average per day in the tropics and subtropics (from $45^{\circ} \mathrm{S}$ to $45^{\circ} \mathrm{N}$ ). These observations have signal-to-noise ratios (SNR) higher than any other RO missions, allowing for deeper penetration into the moist lower troposphere. Thus $\mathrm{C} 2$ observations offer an excellent opportunity to observe the vertical structure of TCs and their environment with unprecedented horizontal RO observation density.

This paper presents a case study that assesses the accuracy of $\mathrm{C} 2$ one-dimensional variational (1D-Var) temperature and specific humidity profiles, and precipitable water in Hurricane Dorian (2019). We compare C2 observations with three model data sets: the European Centre for Medium Range Weather Forecasts (ECMWF) Reanalysis $5^{\text {th }}$ Generation (ERA5), Japan Meteorological Agency 55-Year Reanalysis (JRA-55), and the Modern-Era Retrospective analysis for Research and Applications Version 2 (MERRA-2). We compute biases and standard deviations of the differences of each data set with respect to ERA5 and estimates of the random error standard deviations of these data sets using the three-cornered hat $(3 \mathrm{CH})$ method. To our knowledge, this is the first study of $\mathrm{C} 2$ errors in temperature and specific humidity using the new 1D-Var method (described in section 4.2). We could not compare these estimates to similar estimates of the COSMIC mission because COSMIC was near the end of its lifetime during this period, and very few observations were available.

\section{HURRICANE DORIAN SUMMARY}

Avila et al. (2020) provide an extensive summary of Hurricane Dorian. Dorian formed on 24 August 2019, from a tropical wave in the central Atlantic and gradually strengthened as it moved toward the Lesser Antilles, becoming a hurricane on 28 August (Fig. 1). On 1 September, Dorian reached Category 5 intensity, with maximum sustained winds of $185 \mathrm{mph}\left(82.7 \mathrm{~ms}^{-1}\right)$ and a minimum central pressure of $910 \mathrm{hPa}$ while making landfall in Elbow Cay, Bahamas. The ridge of high pressure steering Dorian westward collapsed on 2 September, causing Dorian to stall just north of Grand Bahama for about a day. It is the strongest known tropical system to impact the Bahamas (Avila et al. 2020). On the morning of 3 September, Dorian began to move slowly towards the north-northwest. Dorian regained Category 3 intensity by midnight on 5 September. In the early hours of 6 September, Dorian weakened to Category 1 intensity as it picked up speed and turned northeast along the North Carolina coast, eventually making landfall at Cape Hatteras. Dorian's track from 24 August to 7 September is depicted in Fig. 1.

Figure 2 shows a visible satellite photograph of Hurricane Dorian and a radar image of Dorian on 1 September as it moved slowly across the Bahamas. These images indicate the extreme cloud and precipitation structure associated with an intense hurricane, and the challenging environment for 3-dimensional remote sensing.

\section{BRIEF DESCRIPTION OF DATA SETS}

Radio occultation (RO) is an active limb-sounding technique that yields high vertical resolution atmospheric profiles and has been shown to have many research and operational uses (Anthes 2011; Bonafoni et al. 2019; Ho et al. 2020a). The RO concept is described by Melbourne et al. (1994) and Kursinski et al. (1997). The vertical resolution of RO profiles is $100 \mathrm{~m}$ to $1 \mathrm{~km}$ depending on the altitude, and the horizontal footprint is $100-300 \mathrm{~km}$ (Anthes 2011; Zeng et al. 2019). We use $C 2$ observations of temperature and specific humidity from the COSMIC Data Analysis and Archival Center (CDAAC) wetPf2, which were obtained using a new 1D-Var procedure described in section 4.2. Precipitable water is computed from the specific humidity. The $\mathrm{C} 2$ data available during the time period used in this study were not assimilated into any of the three models, and hence its errors are considered independent from the errors of the reanalyses.

ERA5 is a state-of-the-art reanalysis and is improved over the widely used ERA-Interim reanalysis (Hersbach et al. 2018). ERA5 has a nominal horizontal resolution of $31 \mathrm{~km}$ and has 137 levels from the surface to $80 \mathrm{~km}$. ERA5 had among the smallest $3 \mathrm{CH}$ error variance estimates of all reanalyses studied by Rieckh et al. (2021). We use ERA5 as a reference to estimate biases in this study because of its quality as well as its high horizontal and vertical resolutions.

JRA-55 is based on the operational system of the Japan Meteorological Agency as of December 2009, and uses past observations from 1958 onwards (Kobayashi et al. 2015). The horizontal resolution of JRA-55 is $55 \mathrm{~km}$ and the 60 model levels extend upward to approximately $60 \mathrm{~km}$.

MERRA-2 is produced by the National Aeronautics and Space Administration (NASA) Global Modeling and Assimilation Office (Gelaro et al. 2017). The horizontal resolution of MERRA-2 is approximately $55 \mathrm{~km}$ in the latitudinal direction. The MERRA-2 model has 72 model levels extending up to $80 \mathrm{~km}$.

We compare the four data sets in two fixed domains over the time period 30 August to 5 September 2019 (day of 


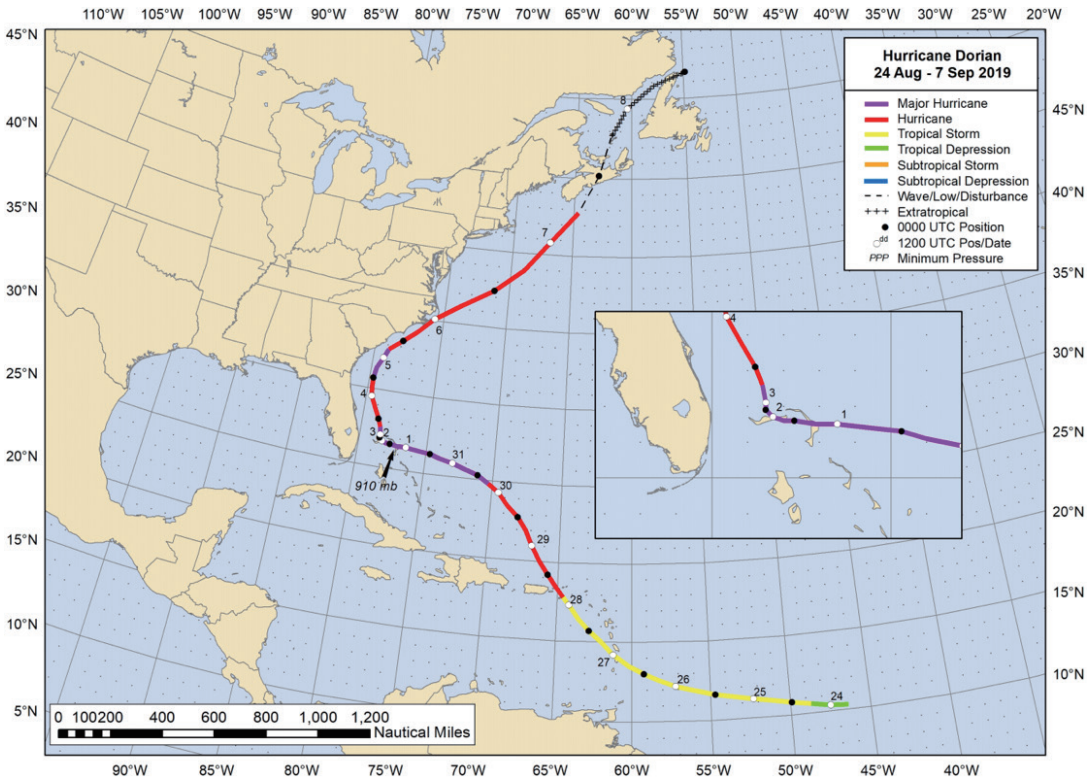

Fig. 1. Best track of Hurricane Dorian (2019) from 24 August to 7 September 2019 (Avila et al. 2020).
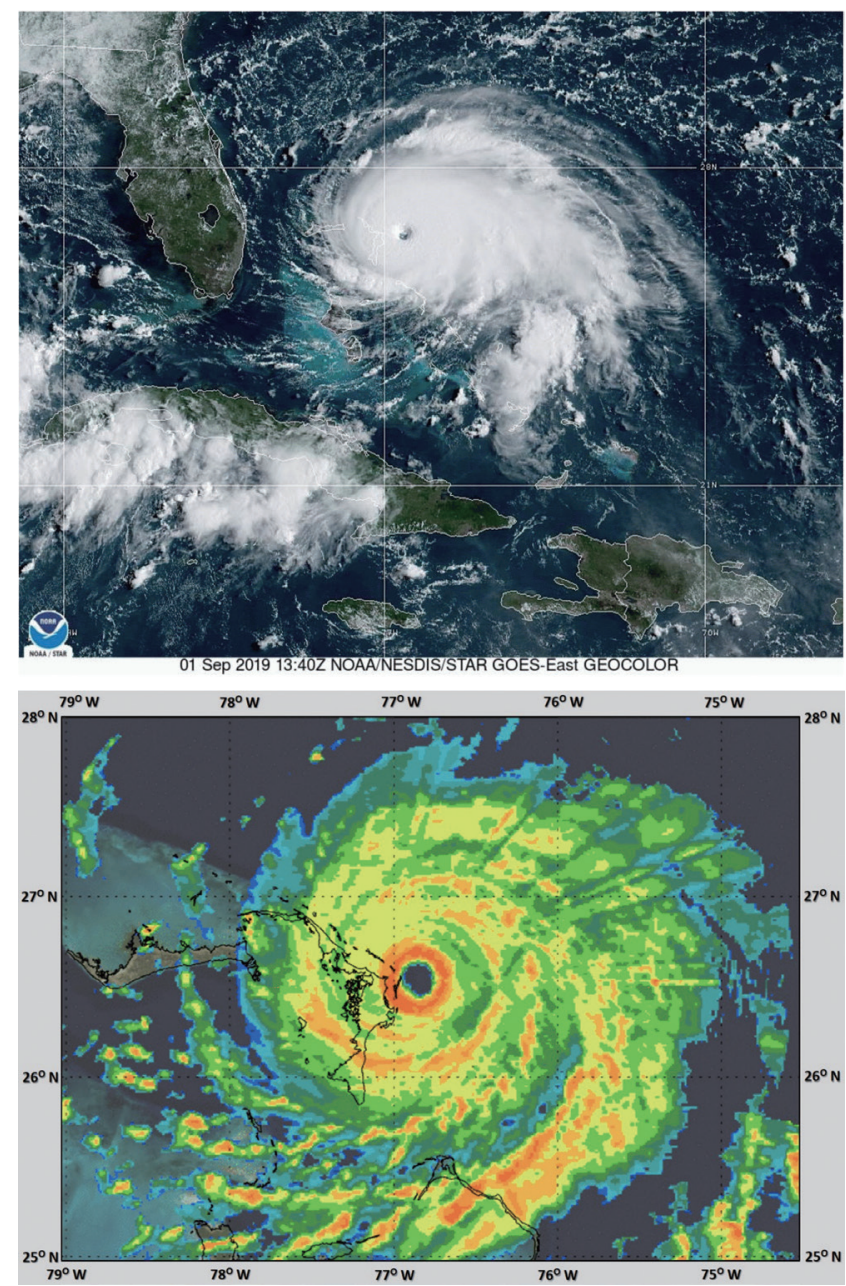

Fig. 2. Top: Visible satellite image of Hurricane Dorian nearly stationary over the Bahamas Islands at 13:40 UTC 1 September 2019. Shown are parallels of latitude 21 and $28^{\circ} \mathrm{N}$ and meridians 70,77 , and $84^{\circ} \mathrm{W}$ (source: NOAA). Bottom: Radar reflectivity of Hurricane Dorian at 15:45 UTC 1 September 2019. Radar data courtesy of the Bahamas Department of Meteorology and image courtesy of Brian McNoldy, RSMAS, U. Miami. 
year 242 - 248): (1) $15-35^{\circ} \mathrm{N}, 86-70^{\circ} \mathrm{W}$ (Dorian window) and (2) the global latitude band $15-35^{\circ} \mathrm{N}$. Figure 3 shows the two fixed domains and the locations of the occultation points of the $\mathrm{C} 2$ soundings provided by CDAAC, with the lowest level above mean sea level (MSL) reached by the soundings indicated by color. The occultation point is the point on Earth's surface to which the retrieved refractivity profile is assigned. It is estimated under the tangent point of the ray connecting the GNSS and LEO satellites for a certain height of the ray asymptote, defined here based on the $\mathrm{L} 1$ excess phase of $500 \mathrm{~m}$, which, on average, corresponds to 3 - $4 \mathrm{~km}$ height (Kuo et al. 2004). There were 229 C2 soundings in the Dorian window with $70 \%$ reaching $1 \mathrm{~km}$ or lower above MSL, and 3704 soundings in the global latitude band with $82 \%$ reaching $1 \mathrm{~km}$ or lower above MSL. We removed outliers from all the data sets by discarding any data that fall outside of either the 0.05 or 99.95 percentiles at each level. This was applied to the global latitude band only and for the data levels whose sample sizes are larger than 1000 . The refractivity values of the reanalysis data sets were computed using the Smith and Weintraub (1953) equation from the model's temperature, water vapor pressure (computed from specific humidity), and pressure. When any of the co-located reanalysis soundings suggest the occurrence of super-refraction (SR), we excluded from the statistics the portions of all soundings below the top of the highest
SR layer because of the known issues caused by SR in RO soundings (Rocken et al. 1997; Ao et al. 2003; Sokolovskiy 2003). SR was considered to occur when the vertical gradient of refractivity was less than $-157 \mathrm{~N}$-units $\mathrm{km}^{-1}$. However, because the reanalyses may not detect all cases of SR, it is likely that at least some of the $\mathrm{C} 2$ profiles were affected by SR and biased negatively.

We also show as examples $18 \mathrm{C} 2$ specific humidity soundings that occurred within $350 \mathrm{~km}$ of the center of Dorian (the approximate radius of the cloud cover as shown in Fig. 2) over the seven days (hurricane domain soundings hereafter). Of these, 16 (89\%) reached $1 \mathrm{~km}$ above MSL or lower and $13(72 \%)$ reached $200 \mathrm{~m}$.

\section{METHODOLOGY}

\subsection{CH Summary}

The $3 \mathrm{CH}$ method for estimating the error variances of three or more data sets simultaneously is a useful tool for intercomparing the error (uncertainty) statistics of multiple instrument, observational, and model data sets (Anthes and Rieckh 2018). Sjoberg et al. (2021) examined the sensitivity of the $3 \mathrm{CH}$ method to factors that limit its accuracy: error correlations, sample size, different magnitudes of random errors, and different vertical resolutions of the data sets. Rieckh et al. (2021) used the $3 \mathrm{CH}$ method to estimate

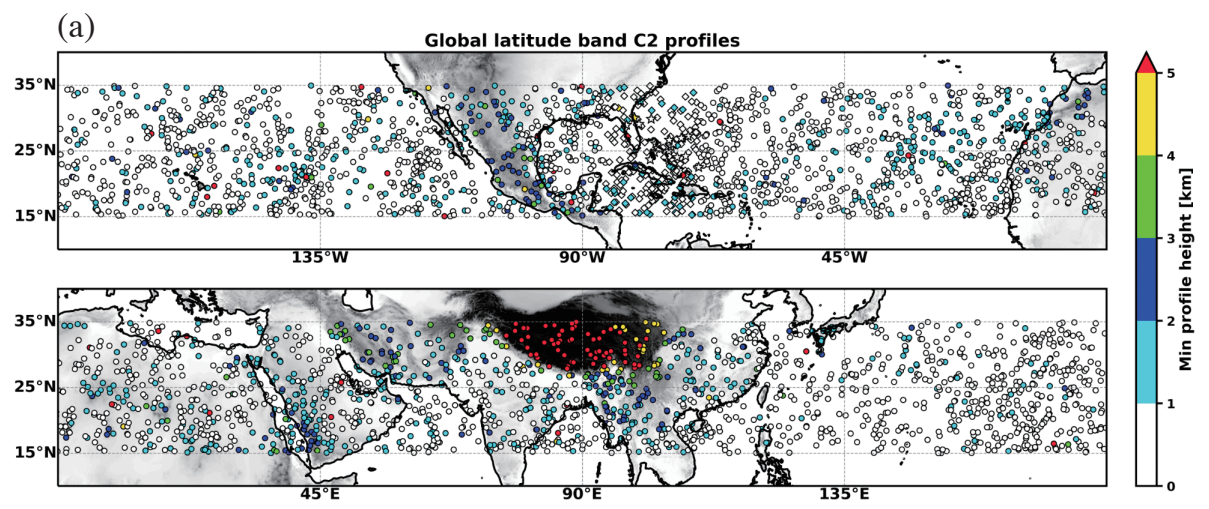

(b) Dorian window C2 profiles

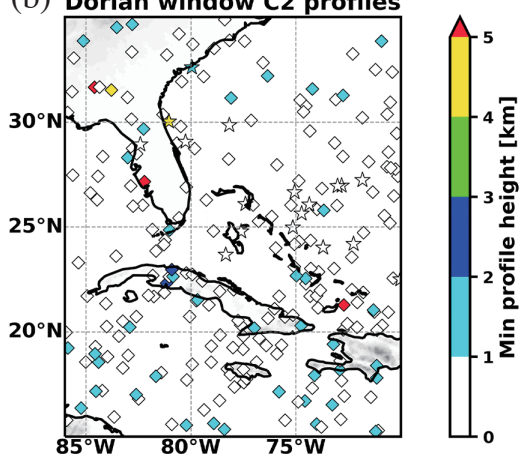

Fig. 3. (a) COSMIC-2 occultations in zonal latitude band from 15 to $35^{\circ} \mathrm{N}$ during the period 30 August to 5 September 2019 . The height of the lowest level of the $\mathrm{C} 2$ penetration is shown by the color coding on the right. Terrain height is indicated by the grey shading. (b) As in Fig. $3 \mathrm{a}$ except for the Dorian window. The stars indicate points lying within the hurricane domain ( $\leq 350 \mathrm{~km}$ from the hurricane center) at some time during the period. 
the errors of COSMIC and $\mathrm{C} 2$, radiosondes, and nine reanalyses, including ERA5, MERRA-2, and JRA-55. They showed how the $3 \mathrm{CH}$ method discriminates among the data sets, how error correlations and representativeness differences affect the error estimates, and how the errors vary with year, latitude, and atmospheric conditions.

The $3 \mathrm{CH}$ equation for the error variance of data set $X$ given three data sets $(X, Y, Z)$ is presented in Eq. (1):

$$
\begin{aligned}
& V^{A R_{\text {err }}}[X] \\
= & 1 / 2\left\{E\left[(X-Y)^{2}\right]+E\left[(X-Z)^{2}\right]-E\left[(Y-Z)^{2}\right]\right\} \\
& -1 / 2\left(b_{X Y}^{2}+b_{X Z}^{2}-b_{Y Z}^{2}\right) \\
& +E\left[\varepsilon_{X} \varepsilon_{Y}\right]+E\left[\varepsilon_{X} \varepsilon_{Z}\right]-E\left[\varepsilon_{Y} \varepsilon_{Z}\right]
\end{aligned}
$$

where $E$ denotes the expected value or sample mean. The random errors $\varepsilon_{X}$ are defined with respect to the unknown "Truth" of the data sets and the bias terms $b_{X Y}$ are the mean biases between two data sets $X$ and $Y$. The error standard deviations are the square root of the error variances (see Sjoberg et al. 2021 for details). All terms can be computed from the co-located data except the error covariance terms, which are unknown and are neglected.

If there are error correlations among any of the data sets, neglect of the error covariance terms will cause inaccurate results of all $3 \mathrm{CH}$ estimates. Error correlations may arise in four ways (Rieckh et al. 2021):

(1) actual error correlations (for example, the correlation of model errors with the errors of observations that are assimilated in the models),

(2) representativeness errors in which data sets have different horizontal or vertical footprints and hence have correlated representativeness differences,

(3) similar errors introduced by the co-location process, and

(4) correlations arising by chance in small sample sizes.

The $3 \mathrm{CH}$ method requires that all data sets be co-located to the same time and location. We first interpolate all gridded model data sets to the time and horizontal location of each $\mathrm{C} 2$ observation. The horizontal locations of $\mathrm{RO}$ observations vary with altitude, as the RO tangent point ranges from 80 to $250 \mathrm{~km}$ (Von Engeln 2006; Healy et al. 2007; Burrows 2015). This drift is considered in our horizontal interpolation scheme. The model data sets and the RO data profiles are interpolated to a common computational height grid of constant interval $100 \mathrm{~m}$. The computational procedure is described in Rieckh et al. (2021), Appendix A.

\subsection{D-Var Retrieval of Temperature and Specific Humidity}

In this study we obtain $\mathrm{C} 2$ soundings of temperature, moisture, and pressure using the most recent version (Wee 2018) of the CDAAC one-dimensional variational inversion algorithm (1D-Var). This version is an improved version of the original CDAAC algorithm that has been in use for many years. The 1D-Var produces physically-constrained soundings of temperature and specific humidity given GNSS RO observed profiles of bending angles. The background, or $a$ priori data set, is the National Centers for Environmental Prediction (NCEP) Global Forecast System (GFS) shortterm forecast interpolated to the time and location of the RO profile (CDAAC avnPrf). The new 1D-Var no longer requires an exact fit to the observations and provides improved temperature and specific humidity profiles (Rieckh et al. 2021). The details of the $1 \mathrm{D}-$ Var algorithm are presented in the Appendix.

\subsection{Precipitable Water}

Precipitable water (PW in $\mathrm{mm}$ ) is defined by

$\mathrm{PW}=\int \rho q d z$

where $\rho$ is the density of moist air $\left(\mathrm{kg} \mathrm{m}^{-3}\right)$ and $q$ is the specific humidity $\left(\mathrm{kg} \mathrm{kg}^{-1}\right)$ and is related to water vapor pressure $e(\mathrm{hPa})$ by

$q=0.622 e /(p-0.378 e)$

where $p$ is pressure (hPa). The integration in Eq. (2) is over height $z$ from the surface to a high level at which the specific humidity becomes negligibly small (here taken to be $15 \mathrm{~km})$.

Most RO observations do not reach the surface, instead terminating at some level $Z_{b}$, which for $\mathrm{C} 2$ is usually $1 \mathrm{~km}$ or lower over the oceans (cf. Fig. 3). Therefore, the RO specific humidity in the layer from $Z_{b}$ to the surface must be estimated in some way to obtain the PW. Previous studies have used different ways of filling in this void (Teng et al. 2013; Fonseca et al. 2018). Here we use the co-located $q$ profile from the GFS short-term forecast (CDAAC avnPrf) at the lowest reported level and linearly interpolate between this value and the $\mathrm{C} 2$ value at $Z_{b}$ to estimate the missing $\mathrm{RO}$ data. The median height of the lowest GFS level is $102 \mathrm{~m}$ in the hurricane domain, $115 \mathrm{~m}$ in the Dorian window, and $118 \mathrm{~m}$ in the global latitude band. The specific humidity below the lowest GFS level is assumed to be constant at the value at the lowest level. Since all of the three model data sets are interpolated to $Z_{b}$ for the $3 \mathrm{CH}$ calculations, we use the model value of $q$ at $Z_{b}$ and the same GFS data to fill in the model data set values. For the PW estimates, we only include C2 profiles that reach $1 \mathrm{~km}$ or lower above sea level (Fig. 3); thus the number of profiles in the PW calculations is smaller than the number used in computing the $3 \mathrm{CH}$ estimates (see Table 1) and emphasizes profiles over the oceans. Because 
of uncertainties introduced by the use of the GFS data below $1 \mathrm{~km}$, we also calculated the PW values from 1 to $15 \mathrm{~km}$.

\section{RESULTS}

In this section we estimate the biases and standard deviations of the differences of all data sets from ERA5 (analogous to $\mathrm{O}-\mathrm{B}$ statistics where $\mathrm{O}$ denotes observations and $\mathrm{B}$ is a background or reference data set). We also estimate the error standard deviations of temperature, specific humidity, and precipitable water of all four data sets using the $3 \mathrm{CH}$ method. The specific humidities of all the data sets are normalized by the sample mean value of ERA5.

\subsection{Mean Specific Humidity and Precipitable Water}

Figure 4 shows the 7-day mean vertical profile of the $\mathrm{C} 2$ specific humidity in the hurricane soundings, in the Dorian window, and over the global latitude band. The corresponding mean ERA5 profiles are also shown. The water vapor within $350 \mathrm{~km}$ of the storm center is significantly higher above $2 \mathrm{~km}$ than in the Dorian window and global latitude band, reflecting the deep moist convective atmosphere of the hurricane. The mean $\mathrm{C} 2$ and ERA5 profiles agree very closely, except below $2 \mathrm{~km}$ where $\mathrm{C} 2$ shows a dry bias in all three domains.

The mean $\mathrm{C} 2$ and ERA5 PW for the three windows are also given in the legend of Fig. 4. The $\mathrm{C} 2$ hurricane mean of $54.70 \mathrm{~mm}$ is considerably larger than the mean PW in the larger domains, but slightly smaller than the ERA5 hurricane mean of $56.26 \mathrm{~mm}$, reflecting the dry bias in $\mathrm{C} 2$ below $2 \mathrm{~km}$. The difference in PW between C2 and ERA5 is largest in the hurricane domain $(1.56 \mathrm{~mm})$, likely because the $\mathrm{C} 2$ profiles penetrate closer to the surface in this domain compared to the other two domains. Thus the GFS values of specific humidity used to fill the gaps between the lowest penetration level and the surface have a greater effect on the $\mathrm{PW}$ values of the other domains, reducing the effect of the dry $\mathrm{C} 2$ bias.

The departures from the Dorian window mean of the $18 \mathrm{C} 2$ hurricane soundings are shown in the right panel of Fig. 4, which illustrates the variability, high vertical resolving power, and penetration depths of these profiles that are near the center of Dorian.

\subsection{Differences of C2, MERRA-2, and JRA-55 from ERA5}

Figure 5 shows the biases and standard deviations of the differences of the C2, MERRA-2, and JRA-55 temperatures to the reference ERA5 for the Dorian window (Fig. 5, left) and the global latitude band (Fig. 5, right). The results are similar in the two regions, indicating that the biases and standard deviations of differences of all data sets compared to ERA5 do not vary much in the hurricane environment compared to the non-hurricane environment. The bias of $\mathrm{C} 2$ temperature oscillates around 0 and is less than $0.3 \mathrm{~K}$ in magnitude between 0 and $15 \mathrm{~km}$. The standard deviation of the $\mathrm{C} 2$ temperature differences is less than $1.0 \mathrm{~K}$.

Figure 6 shows the biases and standard deviations of the refractivity and specific humidity of the three data sets with respect to ERA5. The refractivity biases and standard deviations of the differences are highly correlated with those of specific humidity below $5 \mathrm{~km}$, indicating the dominance of water vapor variations and errors in the refractivity statistics below $5 \mathrm{~km}$. The $\mathrm{C} 2$ specific humidity bias in both domains is negative below $2 \mathrm{~km}$, reaching a maximum magnitude of about $12 \%$ and $2.2 \mathrm{~g} \mathrm{~kg}^{-1}$ (Fig. 6, middle and bottom row). This is related to a negative bias in refractivity reaching $-4.2 \%$ (Fig. 6, top row) in this layer. We found that most (91.5\%) of the $\mathrm{C} 2$ soundings show some negative bias at $500 \mathrm{~m}$. Percentages of $\mathrm{C} 2$ soundings with biases equal to or exceeding the following bias thresholds were $72.9 \%$ (-2\% bias), $44.0 \%$ (-4\% bias), $19.0 \%$ (-6\% bias), $6.8 \%$ (-8\% bias), and $2.2 \%$ ( $-10 \%$ bias).

Schreiner et al. (2020) also found negative refractivity biases for $\mathrm{C} 2$, and Ho et al. (2020b) and Johnston et al. (2021) found dry biases in C2 specific humidity below $2 \mathrm{~km}$. These studies all included profiles with SR, which is known to be a significant cause of negative refractivity biases (Ao et al. 2003; Sokolovskiy 2003; Feng et al. 2020) in the tropics and subtropics.

The widespread negative bias in this study is not mainly related to SR, however, because data were not included in these statistics if SR was detected in soundings of any of the data sets. However, as noted above, the reanalyses may not identify all cases of SR in the real atmosphere, thus some of the $\mathrm{C} 2$ profiles may contain the effects of SR. Rieckh et al. (2021) also found a similar dry bias in C2 compared to ERA5 below $2 \mathrm{~km}$ even though they used the same SR detection and removal process. It is possible that the ERA5 data are biased moist compared to Truth in these comparisons, because the GFS profiles also have a similar dry bias compared to ERA5 below $2 \mathrm{~km}$ (not shown). However, the MERRA-2 and JRA-55 profiles of specific humidity show small biases of both signs in the lowest $2 \mathrm{~km}$ compared to ERA5 (Fig. 6). Furthermore, several of the hurricane C2 profiles that were close in time and space to dropsondes from NOAA reconnaissance aircraft were also biased dry compared to the dropsondes (not shown). Thus we conclude that $\mathrm{C} 2$ refractivity and $1 \mathrm{D}-\mathrm{V}$ ar retrievals of specific humidity likely have a negative bias below $2 \mathrm{~km}$, caused by factors other than or in addition to SR. Feng et al. (2020, section 4b) and Schreiner et al. (2020) summarize possible other causes for these negative biases. These are associated with low SNR values in the complex moist lower troposphere and/ or the propagation of radio waves in an atmosphere with random refractivity perturbations. 
Table 1. Mean PW $(\mathrm{mm})$ and mean error standard deviation estimate $(\mathrm{mm})$ for four data sets. Values in parentheses give the standard deviation of the error estimates. The sample sizes for Dorian window and global latitude bands are 166 and 2197, respectively.

\begin{tabular}{c|cccc}
\hline Data Set & Dorian Window PW $(\mathbf{m m})$ & Dorian Window PW Error $(\mathbf{m m})$ & Zonal PW $(\mathbf{m m})$ & Zonal PW Error $(\mathbf{m m})$ \\
\hline COSMIC-2 & 48.29 & $1.580(0.193)$ & 44.48 & $1.619(0.067)$ \\
ERA5 & 48.89 & $2.028(0.148)$ & 45.47 & $1.842(0.059)$ \\
MERRA-2 & 50.38 & $2.814(0.106)$ & 46.47 & $2.492(0.043)$ \\
JRA-55 & 47.11 & $2.351(0.127)$ & 44.59 & $3.558(0.030)$ \\
\hline
\end{tabular}
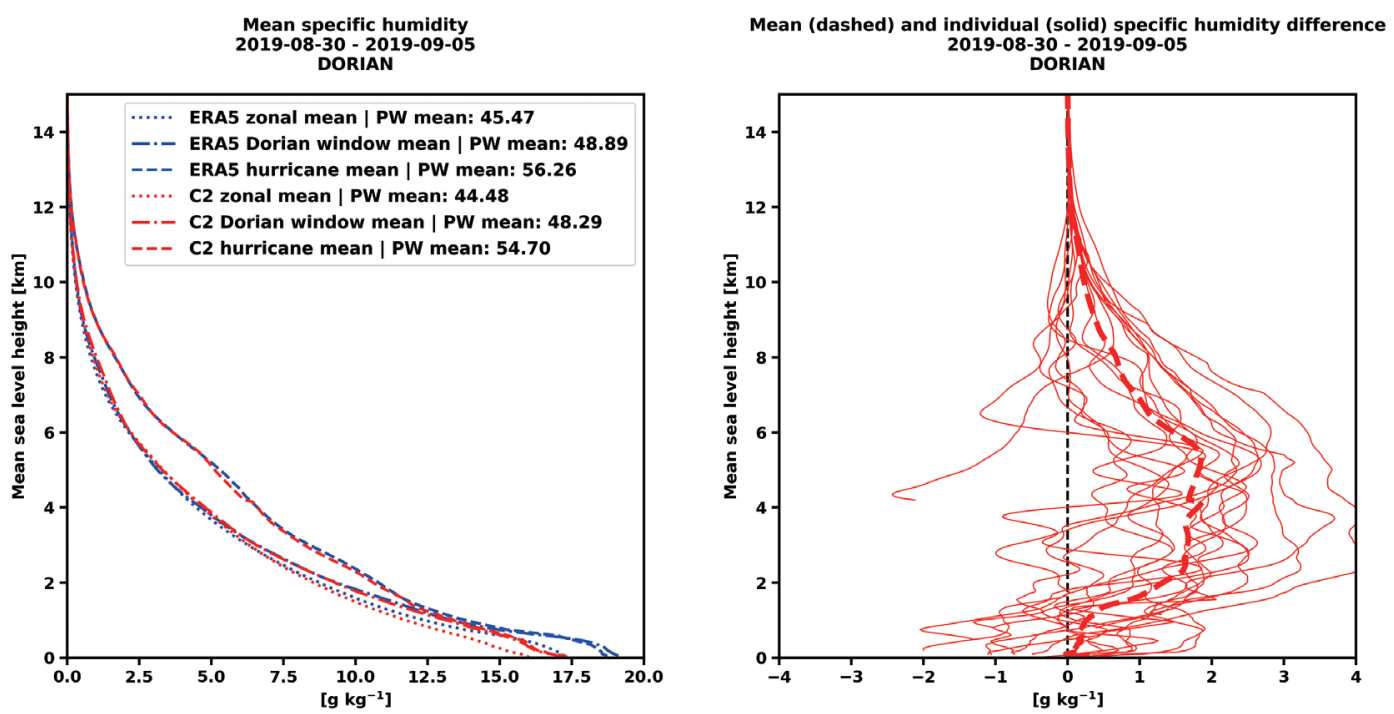

Fig. 4. Left: Mean 7-day specific humidity profile of $\mathrm{C} 2$ (red) in the $15-35^{\circ} \mathrm{N}$ latitude band (dotted), Dorian window (dash-dot), and hurricane soundings (dashed). The corresponding profiles of the mean ERA5 $q$ are shown as blue profiles. Mean PW values (mm) for each domain are shown in the figure legend. Right: Departures from the Dorian window mean $q$ for the 18 individual C2 hurricane soundings. The mean of these departures is indicated by the dashed red profile.
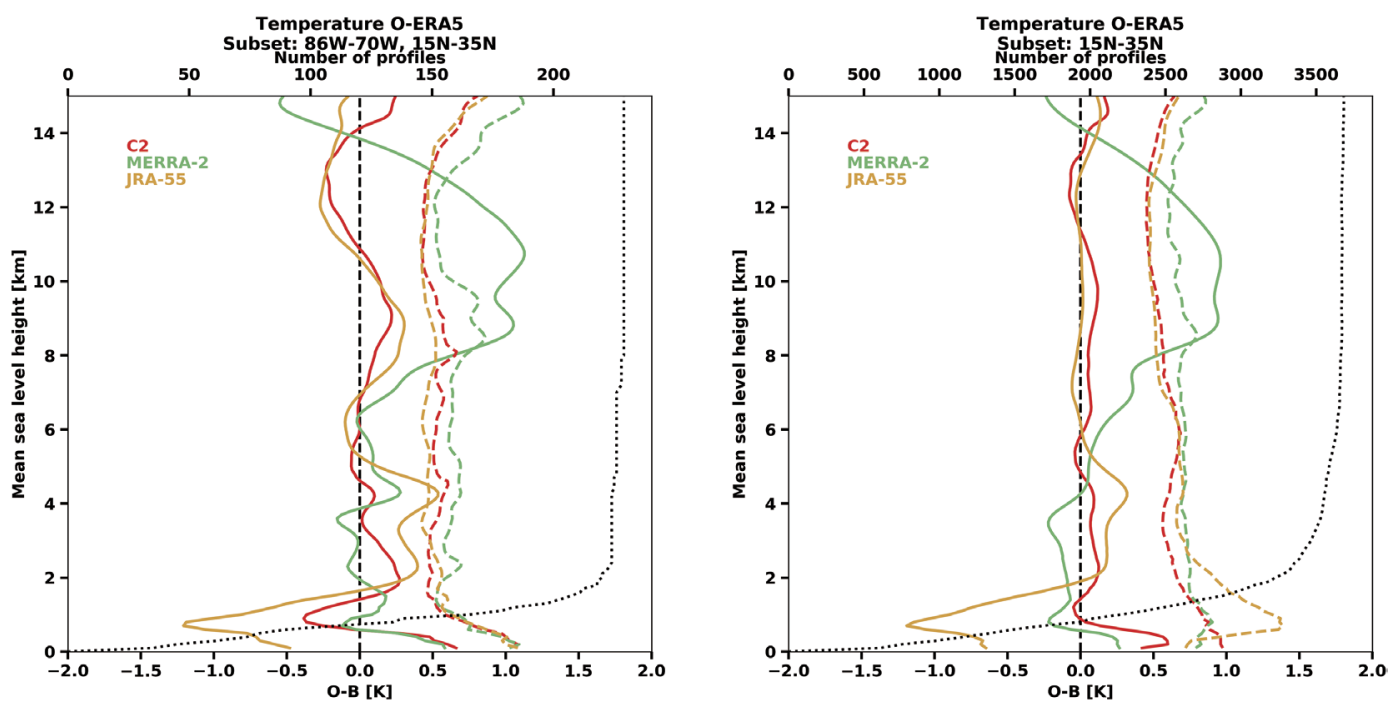

Fig. 5. Mean (solid) and standard deviation (dashed) of temperature differences from ERA5 of C2 (red), MERRA-2 (green), and JRA-55 (orange) for the Dorian window (left) and $15-35^{\circ} \mathrm{N}$ latitude band (right). The sample size at each level, which is determined by $\mathrm{C} 2$, is shown by the black dotted line on the right of each panel. 

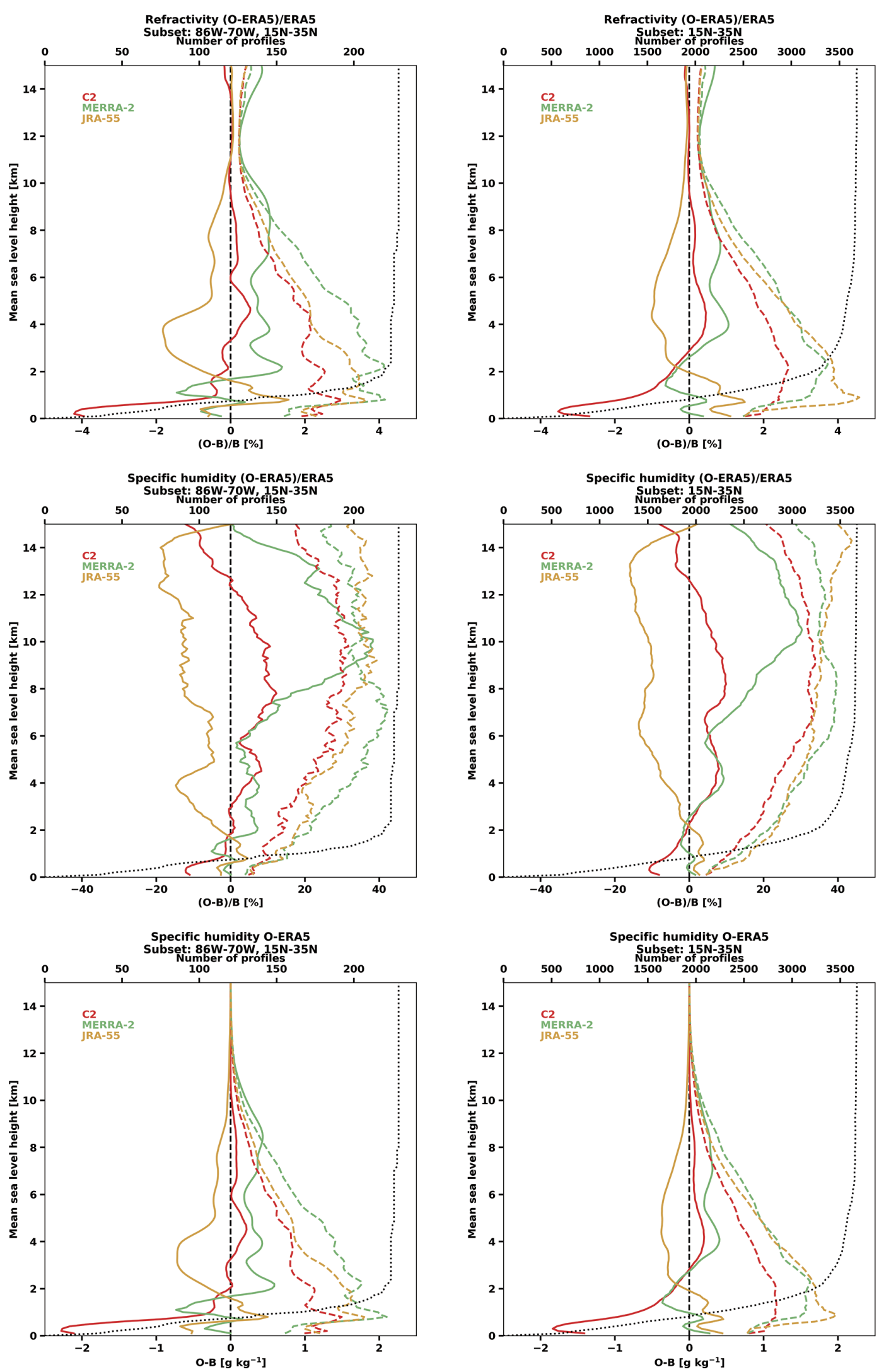

Fig. 6. Mean (solid) and standard deviation (dashed) of differences from ERA5 of C2 (red), MERRA-2 (green), and JRA-55 (orange) for the Dorian window (left) and $15-35^{\circ} \mathrm{N}$ latitude band (right). Top row: normalized refractivity (\%); middle row: normalized specific humidity (\%); bottom row: specific humidity $\left(\mathrm{g} \mathrm{kg}^{-1}\right)$. In the top two rows the refractivity and specific humidity are normalized by the corresponding value of ERA5. 
A small positive bias in $\mathrm{C} 2$ specific humidity occurs throughout most of the troposphere above $2 \mathrm{~km}$. This small bias, and the larger MERRA-2 biases in the upper troposphere, agree with the findings of Johnston et al. (2021). Except for the negative bias below $2 \mathrm{~km}$, the $\mathrm{C} 2$ biases are smaller than those of MERRA-2 and JRA-55. The standard deviation of the differences of $\mathrm{C} 2$ compared to ERA5 are also slightly smaller than those of MERRA-2 and JRA-55, with a maximum of approximately $1.2 \mathrm{~g} \mathrm{~kg}^{-1}$ near $1-2 \mathrm{~km}$ and $35 \%$ near $6-10 \mathrm{~km}$ in the global latitude band.

\subsection{CH Error Estimates for Temperature and Specific Humidity}

Figure 7 shows the $3 \mathrm{CH}$ estimates of the error standard deviations of the temperature (Fig. 7, top row), specific humidity (Fig. 7, middle row), and normalized specific humidity (Fig. 7, bottom row) for the four data sets. The left column corresponds to the Dorian window and the right column to the global $15-35^{\circ} \mathrm{N}$ band. For each of the four data sets, there are three unique triplets and therefore three different estimates of errors. In Fig. 7 we depict the means of these three estimates as solid curves. The +/- 1 standard deviation of the three estimates for each data set are shown by the shading. As discussed by Rieckh et al. (2021), the standard deviation of the estimates is a measure of their uncertainty; in these results the uncertainty is much less than the estimates.

Overall, the error estimate profiles in the Dorian window exhibit greater noise compared to those of the latitude band, which results from the much smaller sample size in the Dorian window. However, the general characteristics of the error estimate profiles do not vary greatly in the two windows, indicating that a sample size as small as 230 can give meaningful results.

The profiles of temperature error estimates (Fig. 7, top row) indicate that the ERA5 errors are smallest below $15 \mathrm{~km}$, followed by JRA-55, C2, and MERRA-2. All error standard deviations are less than $0.75 \mathrm{~K}$. The specific humidity error estimate profiles (middle and bottom rows) indicate that the $\mathrm{C} 2$ error estimates are less than $1 \mathrm{~g} \mathrm{~kg}^{-1}$ at all levels and are comparable to the ERA5 errors, which are slightly smaller than the JRA-55 and MERRA-2 errors.

The overall similarity of the $\mathrm{C} 2$ temperature and specific humidity error profiles in the two windows also indicates that the magnitude of the $\mathrm{C} 2$ random errors does not vary greatly between the hurricane environment and the rest of the tropics and subtropics, illustrating the important characteristic of RO observations being relatively unaffected by clouds and precipitation, even in the environment of an intense hurricane.

\subsection{Precipitable Water Results}

The mean PW values for the four data sets and two domains are shown in Table 1. The PW for all data sets is higher in the Dorian window. The $\mathrm{C} 2 \mathrm{PW}$ is $1-2 \%$ lower than the ERA5 PW because of the negative bias in $\mathrm{C} 2$ specific humidity below $2 \mathrm{~km}$. The PW for the $18 \mathrm{C} 2$ hurricane soundings is $54.70 \mathrm{~mm}$ (see Fig. 4). All of these values are smaller than the maximum PW values reaching $80 \mathrm{~mm}$ that have been observed very close to the center of hurricanes (Zhao et al. 2019). The maximum PW values for the hurricane soundings for the four data sets occurred on 1 September $2019,54.5 \mathrm{~km}$ southeast of the Dorian center, and were: $65.32 \mathrm{~mm}$ (C2), $70.42 \mathrm{~mm}$ (ERA5), $76.76 \mathrm{~mm}$ (MERRA-2), and $61.31 \mathrm{~mm}$ (JRA-55).

The mean $3 \mathrm{CH}$ estimates of the errors in $\mathrm{PW}$ values are shown in the third and fifth columns, with standard deviations of the three estimates shown in parentheses. Because of the small sample size, $3 \mathrm{CH}$ estimates are not shown for the hurricane soundings. The errors in the Dorian window are all between 1.6 and $2.8 \mathrm{~mm}$. The range is somewhat greater for the global latitude band, with $\mathrm{C} 2$ showing the smallest error of near $1.6 \mathrm{~mm}$ and JRA-55 showing the largest error of $3.6 \mathrm{~mm}$. The standard deviation of the $3 \mathrm{CH}$ estimates shows that the uncertainty is small compared to the estimated errors.

Because of the additional uncertainty in the PW estimates introduced by the filling of missing data below the lowest level of $\mathrm{C} 2$, we also compute the PW from 1 to $15 \mathrm{~km}$, which contributes $65 \%$ of the total PW and does not require any filling (Table 2). As expected, the total PW is considerably reduced when the moist lowest $\mathrm{km}$ of the atmosphere is eliminated. The $3 \mathrm{CH}$ estimates of errors are also lower. Without the large negative biases in $\mathrm{C} 2$ specific humidity below $1 \mathrm{~km}$, the $\mathrm{C} 2$ estimates of PW now agree closely with those of ERA5. The C2 estimated random errors are the lowest when the filling of the missing data is not introducing additional uncertainty.

\section{CONCLUSIONS}

We compared COSMIC-2 (C2) radio occultation temperature, specific humidity, and precipitable water with three model data sets (ERA5, MERRA-2, and JRA-55 reanalyses) in the environment of Hurricane Dorian (September 2019) about two months after the launch of C2. The C2 temperature and specific humidity data were obtained using the new COSMIC Data Analysis and Archive Center (CDAAC) 1D-Var retrieval method with the GFS shortrange forecast as the background.

We computed biases and standard deviations of the differences of all the data sets with respect to ERA5 as a reference. We also estimated the random error standard deviations of all four data sets using the three-cornered hat $(3 \mathrm{CH})$ method. We compared the statistics in two regions: the near-hurricane environment (Dorian window) and the $15-35^{\circ} \mathrm{N}$ global latitude band. The sample size varied from 

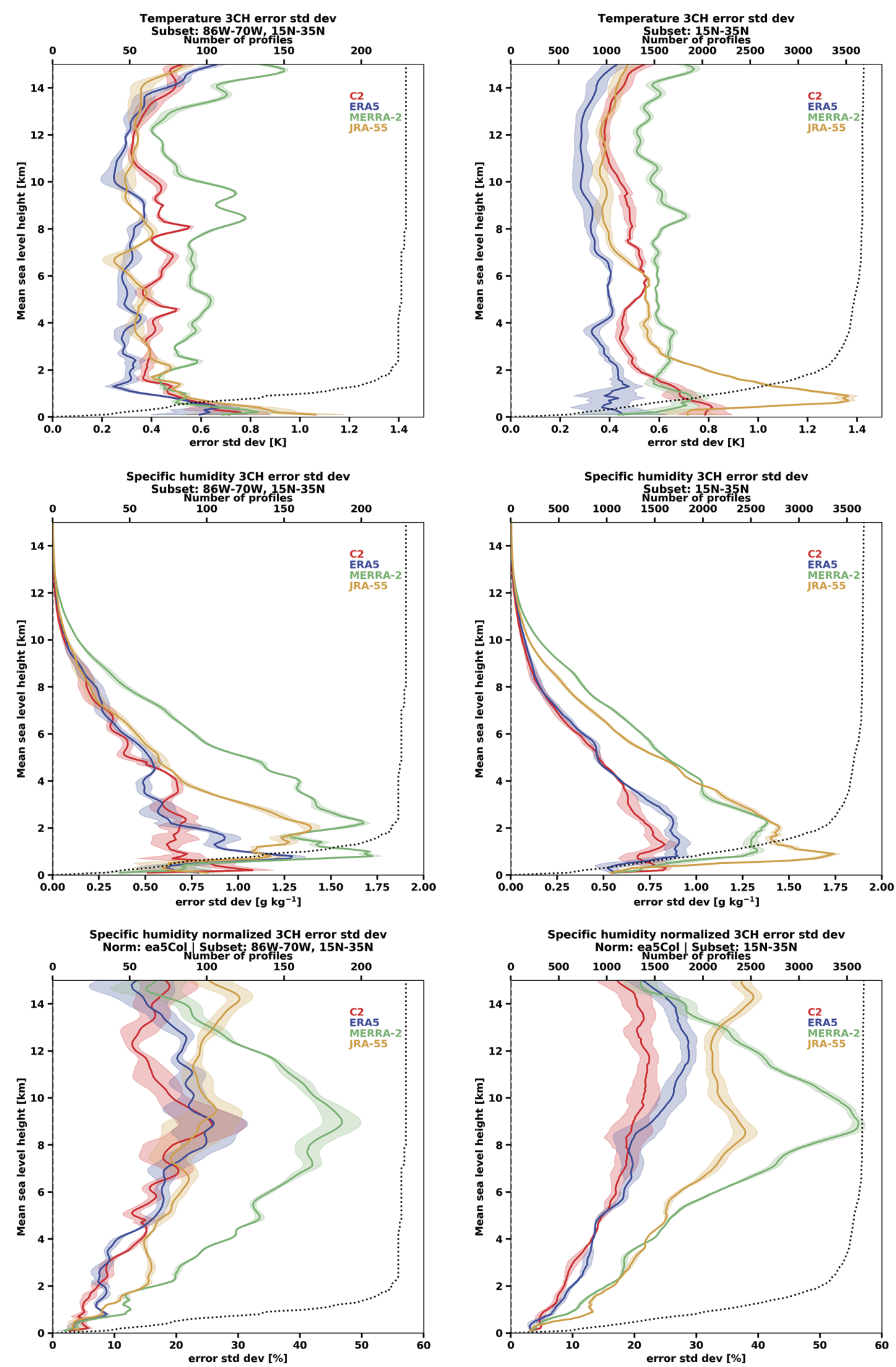

Fig. 7. Mean (solid) and standard deviation (shading) of the $3 \mathrm{CH}$ estimates of error standard deviations of temperature (K, top), specific humidity ( $\mathrm{g} \mathrm{kg}^{-1}$, middle), and normalized specific humidity (\%, bottom) for C2 (red), ERA5 (blue), MERRA-2 (green), and JRA-55 (orange). Left column is for the Dorian window; right column is for the $15-35^{\circ} \mathrm{N}$ latitude band. The sample size is indicated by the dotted profile on the right of each panel. 
Table 2. As in Table 1 except the vertical range for calculating PW is 1 to $15 \mathrm{~km}$.

\begin{tabular}{c|cccc}
\hline Data Set & Dorian Window PW $(\mathbf{m m})$ & Dorian Window PW Error $(\mathbf{m m})$ & Zonal PW $(\mathbf{m m})$ & Zonal PW Error $(\mathbf{m m})$ \\
\hline COSMIC-2 & 32.17 & $1.270(0.181)$ & 29.82 & $1.328(0.074)$ \\
ERA5 & 31.98 & $1.544(0.150)$ & 29.79 & $1.536(0.064)$ \\
MERRA-2 & 33.63 & $2.493(0.094)$ & 30.74 & $2.345(0.043)$ \\
JRA-55 & 29.95 & $2.419(0.097)$ & 28.46 & $3.122(0.032)$ \\
\hline
\end{tabular}

229 in the hurricane window to 3704 in the global band. Despite this large difference in sample size and the extreme moist environment of the hurricane, the error statistics were similar in both regions, confirming that the $\mathrm{C} 2 \mathrm{RO}$ profiles are not significantly degraded by clouds and precipitation in the hurricane.

At least $70 \%$ of all $\mathrm{C} 2$ profiles reached at least $1 \mathrm{~km}$ above MSL in both regions. The biases with respect to ERA5 and the estimated error statistics of the C2 observations compared favorably with those of the other data sets, with the exception of a negative bias in $\mathrm{C} 2$ specific humidity below $2 \mathrm{~km}$. This bias, which occurs in most of the $\mathrm{C} 2$ profiles, is likely associated with factors other than or in addition to super-refraction, as we identified levels of superrefraction in all three reanalyses profiles and excluded the data below these levels from our analysis. Random errors in C2 temperature and specific humidity were estimated to be less than $0.75 \mathrm{~K}$ and $1 \mathrm{~g} \mathrm{~kg}^{-1}(30 \%)$ respectively at all levels, including the hurricane environment.

Precipitable water (PW) estimates in the two regions showed higher water vapor content in the Dorian window compared to the mean global values between $15-35^{\circ} \mathrm{N}$. For example, the mean $\mathrm{C} 2 \mathrm{PW}$ in the Dorian window was $48.3 \mathrm{~mm}$ compared to $44.5 \mathrm{~mm}$ in the global latitude band. Within $350 \mathrm{~km}$ of the Dorian center, the mean PW of 17 C2 soundings was $54.7 \mathrm{~mm}$. The $3 \mathrm{CH}$ estimates of the error standard deviations of the $\mathrm{C} 2 \mathrm{PW}$ for the two domains were $1.58 \mathrm{~mm}(3.3 \%)$ and $1.62 \mathrm{~mm}(3.6 \%)$ respectively, and were the smallest of the four data sets.

These results, although the hurricane sample size is small, indicate that the C2 1D-Var retrieves high quality temperature and water vapor soundings, even in the extreme cloud and precipitation atmosphere of an intense hurricane, as well as in the Northern Hemisphere tropics and subtropics. This is remarkable considering that the error covariance matrices used for the 1D-Var are based on climatological error statistics (Wee 2018) and are not tailored to such extreme weather conditions. This in turn indicates that the information content of $\mathrm{C} 2$ bending angle observations is rich enough to properly constrain the retrievals, overcoming the limitation of using the static error covariance matrices.

Acknowledgements This work has been supported by NSF-NASA grant AGS-1522830 and NOAA contract 16CN0070. We thank Eric DeWeaver (NSF) and Jack Kaye
(NASA) for their long-term support of COSMIC. Data were retrieved from CDAAC (https://cdaac-www.cosmic.ucar. edu) and the NCAR Research Data Archive (https://rda. ucar.edu/). We also acknowledge NOAA, NSF, NASA, the U.S. Air Force and the National Space Office, National Applied Research Laboratory, and the Ministry of Science and Technology in Taiwan for their support of the COSMIC-2 mission. We thank Ben Johnston for his careful review and comments.

\section{REFERENCES}

Anthes, R. A., 2011: Exploring Earth's atmosphere with radio occultation: Contributions to weather, climate and space weather. Atmos. Meas. Tech., 4, 1077-1103, doi: 10.5194/amt-4-1077-2011. [Link]

Anthes, R. A. and T. Rieckh, 2018: Estimating observation and model error variances using multiple data sets. Atmos. Meas. Tech., 11, 4239-4260, doi: 10.5194/amt11-4239-2018. [Link]

Anthes, R. A. and W. Schreiner, 2019: Six new satellites watch the atmosphere over Earth's Equator. Eos, 100, doi: 10.1029/2019EO131779. [Link]

Anthes, R. A., Y.-H. Kuo, C. Rocken, and W. S. Schreiner, 2003: Atmospheric sounding using GPS radio occultation. MAUSAM, 54, 25-38, doi: 10.54302/mausam. v54i1.1489. [Link]

Ao, C. O., T. K. Meehan, G. A. Hajj, A. J. Mannucci, and G. Beyerle, 2003: Lower troposphere refractivity bias in GPS occultation retrievals. J. Geophys. Res., 108, 4577, doi: 10.1029/2002JD003216. [Link]

Avila, L. A., S. R. Stewart, R. Berg, and A. B. Hagen, 2020: Hurricane Dorian (AL052019). National Hurricane Center Tropical Cyclone Report, 74 pp. Available at https://www.nhc.noaa.gov/data/tcr/AL052019 Dorian.pdf.

Biondi, R., T. Neubert, S. Syndergaard, and J. K. Nielsen, 2011: Radio occultation bending angle anomalies during tropical cyclones. Atmos. Meas. Tech., 4, 10531060, doi: 10.5194/amt-4-1053-2011. [Link]

Biondi, R., S.-P. Ho, W. Randel, S. Syndergaard, and T. Neubert, 2013: Tropical cyclone cloud-top height and vertical temperature structure detection using GPS radio occultation measurements. J. Geophys. Res., 118, 
5247-5259, doi: 10.1002/jgrd.50448. [Link]

Biondi, R., A. K. Steiner, G. Kirchengast, and T. Rieckh, 2015: Characterization of thermal structure and conditions for overshooting of tropical and extratropical cyclones with GPS radio occultation. Atmos. Chem. Phys., 15, 5181-5193, doi: 10.5194/acp-15-5181-2015. [Link]

Bonafoni, S., R. Biondi, H. Brenot, and R. Anthes, 2019: Radio occultation and ground-based GNSS products for observing, understanding and predicting extreme events: A review. Atmos. Res., 230, 104624, doi: 10.1016/j.atmosres.2019.104624. [Link]

Burrows, C., 2015: Progress in assimilating radio occultation data at the Met Office. IROWG-4, Melbourne, Victoria, Australia, International Radio Occultation Working Group, 62 pp. Available at http://irowg. org/wpcms/wp-content/uploads/2014/05/BurrowsIROWG-4.pdf.

Chen, S.-Y., C.-Y. Huang, Y.-H. Kuo, Y.-R. Guo, and S. Sokolovskiy, 2009: Assimilation of GPS refractivity from FORMOSAT-3/COSMIC using a nonlocal operator with WRF 3DVAR and its impact on the prediction of a typhoon event. Terr. Atmos. Ocean. Sci., 20, 133-154, doi: 10.3319/TAO.2007.11.29.01(F3C). [Link]

Chen, S.-Y., Y.-H. Kuo, and C.-Y. Huang, 2020: The Impact of GPS RO Data on the Prediction of Tropical Cyclogenesis Using a Nonlocal Observation Operator: An Initial Assessment. Mon. Weather Rev., 148, 27012717, doi: 10.1175/MWR-D-19-0286.1. [Link]

Chen, Y.-C., M.-E. Hsieh, L.-F. Hsiao, Y.-H. Kuo, M.-J. Yang, C.-Y. Huang, and C.-S. Lee, 2015: Systematic evaluation of the impacts of GPSRO data on the prediction of typhoons over the northwestern Pacific in 2008-2010. Atmos. Meas. Tech., 8, 2531-2542, doi: 10.5194/amt-8-2531-2015. [Link]

Chou, M.-D., C.-H. Weng, and P.-H. Lin, 2009: Analyses of FORMOSAT-3/COSMIC humidity retrievals and comparisons with AIRS retrievals and NCEP/NCAR reanalyses. J. Geophys. Res., 114, D00G03, doi: 10.1029/2008JD010227. [Link]

Courtier, P., J.-N. Thépaut, and A. Hollingsworth, 1994: A strategy for operational implementation of 4D-Var, using an incremental approach. Q.J.R. Meteorol. Soc., 120, 1367-1387, doi: 10.1002/qj.49712051912. [Link]

Feng, X., F. Xie, C. O. Ao, and R. A. Anthes, 2020: Ducting and biases of GPS radio occultation bending angle and refractivity in the moist lower troposphere. $J$. Atmos. Ocean. Technol., 37, 1013-1025, doi: 10.1175/ JTECH-D-19-0206.1. [Link]

Fonseca, Y. B., P. Alexander, A. de la Torre, R. Hierro, P. LLamedo, and A. Calori, 2018: Comparison between GNSS ground-based and GPS radio occultation precipitable water observations over ocean-dominated regions. Atmos. Res., 209, 115-122, doi: 10.1016/j.atmosres.2018.03.017. [Link]

Gelaro, R., W. McCarty, M. J. Suárez, R. Todling, A. Molod, L. Takacs, C. A. Randles, A. Darmenov, M. G. Bosilovich, R. Reichle, K. Wargan, L. Coy, R. Cullather, C. Draper, S. Akella, V. Buchard, A. Conaty, A. M. da Silva, W. Gu, G.-K. Kim, R. Koster, R. Lucchesi, D. Merkova, J. E. Nielsen, G. Partyka, S. Pawson, W. Putman, M. Rienecker, S. D. Schubert, M. Sienkiewicz, and B. Zhao, 2017: The Modern-Era Retrospective Analysis for Research and Applications, Version 2 (MERRA-2). J. Clim., 30, 5419-5454, doi: 10.1175/ JCLI-D-16-0758.1. [Link]

Healy, S. B., J. R. Eyre, M. Hamrud, and J.-N. Thepaut, 2007: Assimilating GPS radio occultation measurements with two-dimensional bending angle observation operators. Q.J.R.Meteorol. Soc., 133, 1213-1227, doi: 10.1002/qj.63. [Link]

Hedin, A. E., 1991: Extension of the MSIS Thermosphere Model into the middle and lower atmosphere. J. Geophys. Res., 96, 1159-1172, doi: 10.1029/90JA02125. [Link]

Hersbach, H., P. de Rosnay, B. Bell, D. Schepers, A. Simmons, C. Soci, S. Abdalla, M. Alonso-Balmaseda, G. Balsamo, P. Bechtold, P. Berrisford, J.-R. Bidlot, E. de Boisséson, M. Bonavita, P. Browne, R. Buizza, P. Dahlgren, D. Dee, R. Dragani, M. Diamantakis, J. Flemming, R. Forbes, A. J. Geer, T. Haiden, E. Hólm, L. Haimberger, R. Hogan, A. Horányi, M. Janisková, P. Laloyaux, P. Lopez, J. Muñoz-Sabater, C. Peubey, R. Radu, D. Richardson, J.-N. Thépaut, F. Vitart, X. Yang, E. Zsótér, and H. Zuo, 2018: Operational global reanalysis: Progress, future directions and synergies with NWP. ECMWF ERA Report Series 27, doi: 10.21957/tkic6g3wm. [Link]

Ho, S.-P., R. A. Anthes, C. O. Ao, S. Healy, A. Horanyi, D. Hunt, A. J. Mannucci, N. Pedatella, W. J. Randel, A. Simmons, A. Steiner, F. Xie, X. Yue, and Z. Zeng, 2020a: The COSMIC/FORMOSAT-3 radio occultation mission after 12 years: Accomplishments, remaining challenges, and potential impacts of COSMIC-2. Bull. Amer. Meteorol. Soc., 101, E1107-E1136, doi: 10.1175/BAMS-D-18-0290.1. [Link]

Ho, S.-P., X. Zhou, X. Shao, B. Zhang, L. Adhikari, S. Kireev, Y. He, J. G. Yoe, W. Xia-Serafino, and E. Lynch, 2020b: Initial assessment of the COSMIC-2/ Formosat-7 neutral atmosphere data quality in NESDIS/STAR using in situ and satellite data. Remote Sens., 12, 4099, doi: 10.3390/rs12244099. [Link]

Hollingsworth, A. and P. Lönnberg, 1986: The statistical structure of short-range forecast errors as determined from radiosonde data. Part I: The wind field. Tellus A, 38A, 111-136, doi: 10.1111/j.1600-0870.1986. tb00460.x. [Link] 
Huang, C.-Y., Y.-H. Kuo, S.-H. Chen, and F. Vandenberghe, 2005: Improvements in typhoon forecasts with assimilated GPS occultation refractivity. Weather Forecast., 20, 931-953, doi: 10.1175/WAF874.1. [Link]

Huang, C.-Y., Y.-H. Kuo, S.-Y. Chen, C.-T. Terng, F.-C. Chien, P.-L. Lin, M.-T. Kueh, S.-H. Chen, M.-J. Yang, C.-J. Wang, and A. S. K. A. V. Prasad Rao, 2010: Impact of GPS radio occultation data assimilation on regional weather predictions. GPS Solut., 14, 35-49, doi: 10.1007/s10291-009-0144-1. [Link]

Johnston, B. R., W. J. Randel, and J. P. Sjoberg, 2021: Evaluation of tropospheric moisture characteristics among COSMIC-2, ERA5 and MERRA-2 in the tropics and subtropics. Remote Sens., 13, 880, doi: 10.3390/ rs 13050880. [Link]

Kobayashi, S., Y. Ota, Y. Harada, A. Ebita, M. Moriya, H. Onoda, K. Onogi, H. Kamahori, C. Kobayashi, H. Endo, K. Miyaoka, and K. Takahashi, 2015: The JRA-55 Reanalysis: General specifications and basic characteristics. J. Meteorol. Soc. Jpn., 93, 5-48, doi: 10.2151/jmsj.2015-001. [Link]

Kueh, M.-T., C.-Y. Huang, S.-Y. Chen, S.-H. Chen, and C.-J. Wang, 2009: Impact of GPS radio occultation refractivity soundings on a simulation of Typhoon Bilis (2006) upon landfall. Terr. Atmos. Ocean. Sci., 20, 115-131, doi: 10.3319/TAO.2008.01.21.03(F3C). [Link]

Kuo, Y.-H., T.-K. Wee, S. Sokolovskiy, C. Rocken, W. Schreiner, D. Hunt, and R. A. Anthes, 2004: Inversion and error estimation of GPS radio occultation data. J. Meteorol. Soc. Jpn., 82, 507-531, doi: 10.2151/ jmsj.2004.507. [Link]

Kursinski, E. R., G. A. Hajj, J. T. Schofield, R. P. Linfield, and K. R. Hardy, 1997: Observing Earth's atmosphere with radio occultation measurements using the Global Positioning System. J. Geophys. Res., 102, 2342923465, doi: 10.1029/97JD01569. [Link]

Lewis, J. M. and J. C. Derber, 1985: The use of adjoint equations to solve a variational adjustment problem with advective constraints. Tellus A, 37, 309-322, doi: 10.3402/tellusa.v37i4.11675. [Link]

Liu, H., J. Anderson, and Y.-H. Kuo, 2012: Improved analyses and forecasts of Hurricane Ernesto's genesis using radio occultation data in an ensemble filter assimilation system. Mon. Weather Rev., 140, 151-166, doi: 10.1175/MWR-D-11-00024.1. [Link]

Melbourne, W. G., E. S. Davis, C. B. Duncan, G. A. Hajj, K. R. Hardy, E. R. Kursinski, T. K. Meehan, L. E. Young, and T. P. Yunck, 1994: The application of spaceborne GPS to atmospheric limb sounding and global change monitoring. Contractor Report, JPL Publication 9418, Jet Propulsion Laboratory, California Institute of Technology, 142 pp. Available at https://ntrs.nasa.gov/ archive/nasa/casi.ntrs.nasa.gov/19960008694.pdf.
Parrish, D. F. and J. C. Derber, 1992: The National Meteorological Center's spectral statistical-interpolation analysis system. Mon. Weather Rev., 120, 1747-1763, doi: 10.1175/1520-0493(1992)120<1747:TNMCSS $>2$ .0.CO;2. [Link]

Rieckh, T., J. P. Sjoberg, and R. A. Anthes, 2021: The three-cornered hat method for estimating error variances of three or more atmospheric datasets. Part II: Evaluating radio occultation and radiosonde observations, global model forecasts, and reanalyses. J. Atmos. Ocean. Technol., 38, 1777-1796, doi: 10.1175/ JTECH-D-20-0209.1. [Link]

Rocken, C., R. Anthes, M. Exner, D. Hunt, S. Sokolovskiy, R. Ware, M. Gorbunov, W. Schreiner, D. Feng, B. Herman, Y. -H. Kuo, and X. Zou, 1997: Analysis and validation of GPS/MET data in the neutral atmosphere. J. Geophys. Res., 102, 29849-29866, doi: 10.1029/97JD02400. [Link]

Schreiner, W. S., J. P. Weiss, R. A. Anthes, J. Braun, V. Chu, J. Fong, D. Hunt, Y.-H. Kuo, T. Meehan, W. Serafino, J. Sjoberg, S. Sokolovskiy, E. Talaat, T. K. Wee, and Z. Zeng, 2020: COSMIC-2 radio occultation constellation: First results. Geophys. Res. Lett., 47, e2019GL086841, doi: 10.1029/2019GL086841. [Link]

Sjoberg, J. P., R. A. Anthes, and T. Rieckh, 2021: The threecornered hat method for estimating error variances of three or more atmospheric datasets. Part I: Overview and evaluation. J. Atmos. Ocean. Technol., 38, 555572, doi: 10.1175/JTECH-D-19-0217.1. [Link]

Smith, E. K. and S. Weintraub, 1953: The constants in the equation for atmospheric refractive index at radio frequencies. Journal of Research of the Notional Bureau of Standards, 50, 39-41. Available at https://nvlpubs. nist.gov/nistpubs/jres/50/jresv50n1p39 A1b.pdf.

Sokolovskiy,S.,2003: Effect of superrefraction on inversions of radio occultation signals in the lower troposphere. Radio Sci., 38, 1058, doi: 10.1029/2002RS002728. [Link]

Teng, W.-H., C.-Y. Huang, S.-P. Ho, Y.-H. Kuo, and X.J. Zhou, 2013: Characteristics of global precipitable water in ENSO events revealed by COSMIC measurements. J. Geophys. Res., 118, 8411-8425, doi: 10.1002/ jgrd.50371. [Link]

Vergados, P., A. J. Mannucci, and H. Su, 2013: A validation study for GPS radio occultation data with moist thermodynamic structure of tropical cyclones. J. Geophys. Res., 118, 9401-9413, doi: 10.1002/jgrd.50698. [Link]

Von Engeln, A., 2006: An analysis of CHAMP radio occultation data. Forecasting Research Technical Report 471, Met Office, Exeter, U.K.

Wee, T.-K., 2018: A variational regularization of Abel transform for GPS radio occultation. Atmos. Meas. Tech., 11, 1947-1969, doi: 10.5194/amt-11-19472018. [Link] 
Zeng, Z., S. Sokolovskiy, W. S. Schreiner, and D. Hunt, 2019: Representation of vertical atmospheric structures by radio occultation observations in the upper troposphere and lower stratosphere: Comparison to high-resolution radiosonde profiles. J. Atmos. Ocean. Technol., 36, 655-670, doi: 10.1175/JTECHD-18-0105.1. [Link]

Zhao, Q., X. Ma, W. Yao, and Y. Yao, 2019: A New Typhoon-Monitoring Method Using Precipitation Water Vapor. Remote Sens., 11, 2845, doi: 10.3390/ rs11232845. [Link]

Zhu, C., R. H. Byrd, P. Lu, and J. Nocedal, 1997: Algorithm 778: L-BFGS-B: Fortran subroutines for large-scale bound-constrained optimization. ACM Trans. Math. Software, 23, 550-560, doi: 10.1145/279232.279236. [Link]

\section{APPENDIX. THE 1D-VAR RETRIEVAL OF TEMPERATURE AND SPECIFIC HUMIDITY}

The CDAAC 1D-Var used in this study (Wee 2018) is built upon the incremental formulation (Courtier et al. 1994) and makes use of the control-variable transform (Parrish and Derber 1992) to provide physically-constrained thermodynamic soundings which are of the most likely, subject to a given set of RO observations, the background (a priori), and their error covariance matrices (ECMs). The desired thermodynamic soundings are retrieved at the minimum of a quadratic cost function, attained through a Newtontype iteration for which the gradient of the cost function is calculated with the adjoint technique (e.g., Lewis and Derber 1985), which offers an efficient means to evaluate the gradient, while the steepest descent of the cost function is searched with the aid of a quasi-Newtonian limited-memory algorithm for large-scale optimization (Zhu et al. 1997).

The observation type used by the 1D-Var is the atmospheric (ionosphere-corrected) bending angle for which the Abel transform of the refractivity is used as the forward model. One of the issues with the Abel transform is that the model sounding simulates not only the bending angle but also its location (impact parameter). The model error projected onto the impact parameter introduces considerable error to the interpreted location of the observation, which in turn produces extra - potentially significant - representativeness error in the lower troposphere (Wee 2018). To address this issue, we undertake two separate, sequential
1D-Var minimizations: (1) The refractivity as a function of the impact parameter (the lone state/control variable) is variationally determined from observed bending angle via the Abel transform, which, upon completion, gives the height of the refractivity as per the definition of the refractional radius. (2) The next step is a regular 1D-Var procedure for which the "optimal" refractivity acquired from the prior step as a function of height is used as the observation to give soundings of temperature, moisture, and pressure. The essence of this two-step approach lies in that the retrieval problem is broken down into separate well-defined minimization problems in which the observation and the solution reside always in the same coordinate, which avoids the transform between the height and the refractional radius - and the uncertainty associated with it - in the course of each minimization. The control variables used in the second minimization are a temperature sounding (covering the entire height range), a sounding of the pseudo (in reference to the background temperature) relative humidity $(<30 \mathrm{~km})$, and the pressure at the lowest height. The state variables are constrained in such a way that the virtual temperature and pressure are in hydrostatic balance and the moisture remains non-negative and sub-saturated.

The background provided for the lower part of the 1DVar domain is a short-term NCEP GFS forecast (CDAAC avnPrf), interpolated to the location and time of each $\mathrm{C} 2$ sounding. The $\mathrm{C} 2$ sounding is extended above the model top, mainly for the Abel transform, with a four-dimensional (available monthly and at 00, 06, 12, 18 UTC) climatology of the ECMWF analysis and with the empirical model of the US Naval Research Laboratory, MSIS (Hedin 1991), above the ECMWF model top. The 1D-Var makes use of two auxiliary data sets, one of which contains the observation ECMs diagnosed at every $5^{\circ}$ in latitude and for each month of the year by applying the Hollingsworth-Lönnberg method (Hollingsworth and Lönnberg 1986) to $\sim 1.5$ million nearby pairs of COSMIC soundings available for years 2007 through 2014, and the other of which holds the background ECMs estimated through the NMC (National Meteorological Center) method (Parrish and Derber 1992), available monthly at every $10^{\circ}$ in latitude and longitude. The ECMs are taken at the location nearest to each individual $\mathrm{C} 2$ sounding. The background ECM takes into account cross (inter-variable) error correlations, while the observation ECM is purely diagonal and no attempt is made to adjust the diagonal elements in magnitude for $\mathrm{C} 2$. 